\title{
Análise de conjuntura eclesial na perspectiva do ecumenismo
}

Francisco Biasin e assessoria da Comissão de Ecumenismo e Diálogo Inter-religioso da CNBB $57^{\mathrm{a}}$ Assembleia Geral da CNBB, 1 de maio de 2019

\section{INTRODUÇÃO}

Fazer análise de conjuntura eclesial implica em falar de ecumenismo, não apenas para tratar das relações ad extra da Igreja, mas para analisar algo que lhe é constitutivo, uma nota própria: a unidade. Como ensina São João Paulo II, "querer a unidade significa querer a Igreja" (Ut unum sint, 9); "O ecumenismo ... não é um tipo de apêndice que se junta à atividade tradicional da Igreja. Pelo contrário, pertence organicamente à sua vida e ação, devendo, por conseguinte, permear a Igreja no seu todo, até alcançar seu pleno desenvolvimento" (Ut unum sint, 20). Podemos, então, afirmar uma "relação identitária entre igreja e ecumenismo" (WOLFF, E., A unidade da Igreja, p. 14) porque diz respeito à comunhão na fé entre quem pelo Batismo se insere no Corpo de Cristo. Em nossa análise focaremos três elementos: a história, o momento atual e perspectivas futuras do ecumenismo no Brasil.

\section{A HISTÓRIA}

O movimento ecumênico no Brasil tem mais de um século de história, se considerarmos que os seus primeiros impulsos foram dados com a Aliança Evangélica Brasileira (1903), depois Comissão Brasileira de Cooperação (1920) e outras organizações similares nos inícios do século XX. Tratava-se de organizações evangélicas em busca de cooperação na missão. Como em outras partes do mundo, o ecumenismo no Brasil nasceu em meios protestantes. Até o advento do concílio Vaticano II, a Igreja católica manteve-se distante do movimento ecumênico, por razões já bem conhecidas. Mas com esse Concílio os cristãos católicos em todo o mundo foram incentivados e orientados a se integrarem nos caminhos da unidade cristã. Grande incentivo foi dado também nas Assembleias dos bispos da América Latina de Medellín até Aparecida. E na CNBB foram dados os primeiros passos nessa direção com o Plano Pastoral de Conjunto (1966), criando a "Linha 5" para orientar a prática ecumênica. A partir de então membros da CNBB compuseram organizações ecumênicas de diferentes naturezas, como a CESE (1973) e o CONIC (1982) em âmbito nacional. Quase contemporaneamente iniciou-se uma parceria em organismos ecumênicos regionais, como SICA (Porto Alegre, 1969), CIER (Santa Catarina, 
Análise de conjuntura eclesial na perspectiva do ecumenismo 1970), MOVEC (Curitiba, anos 60), CAIC (Amazônia) entre outros, além da representação da parte católica nas diversas "Representações Regionais" do CONIC.

Ainda, pela CNBB a Igreja católica no Brasil desenvolve um diálogo bilateral com algumas Igrejas pelas Comissões: Católica - Luterana (1974); Católica - Anglicana (1982) e Católica - Judaica (1998). Em 2009 foi criada a Comissão Católica-Presbiteriana Unida, mas esta ainda não conseguiu se estruturar como tal.

Assim foi possível realizar e desenvolver um diálogo multilateral pelas organizações ecumênicas; e bilateral pelas Comissões específicas. Cada um desses organismos ecumênicos tem sua dinâmica própria, uma pauta específica para o diálogo e um modo de agir, conforme a configuração que lhe é dada pelos seus contextos e sua membresia. Isso significa que o diálogo ecumênico acontece de modo situado, procurando responder às demandas da fé cristã em realidades bem concretas e ao mesmo tempo diversificadas.

\section{O PRESENTE}

Que frutos podem ser colhidos do cultivo da planta ecumênica? Onde foi possível chegar no caminho percorrido? Destacamos uma maior fraternidade entre as Igrejas pelo reconhecimento mútuo do batismo e pela afirmação dos valores do diálogo e do respeito mútuo, a prática da cooperação, o aumento da procura pela formação ecumênica, a intensificação da espiritualidade do diálogo. Assim é possível sistematizar alguns dos resultados em três principais horizontes.

\subsection{Social}

A causa ecumênica tem fortalecido as Igrejas como solidárias às vicissitudes sociais do nosso povo, e assim aprendemos a trabalhar de forma cooperativa. Desenvolvemos um "ecumenismo de base", priorizando a promoção humana, a justiça social, o bem-estar geral, a moralidade pública e privada e o cuidado com o meio ambiente. São significativas as inúmeras Declarações Ecumênicas sobre situações específicas da nação brasileira (cfr. site do CONIC), a preparação e a vivência das 4 Campanhas da Fraternidade Ecumênicas, os projetos sociais da CESE entre outros. Tais iniciativas nos exercitam no testemunho comum do Evangelho, juntando recursos e esforços para promover todas as formas de vida humana e do planeta.

\subsection{Teológico}

A nossa participação nos diálogos multilaterais e bilaterais possibilitam estabelecer acordos oficiais com outras Igrejas, como o mútuo reconhecimento do Batismo entre as Igrejas membro do CONIC (1978 e renovado em 2007), e apontar convergências e consensos sobre diversos temas teológicos. Dos seminários de estudos promovidos pelo CONIC identificamos importantes convergências na doutrina das Igrejas sobre: Hospitalidade Eucarística (1999), Igrejas e Ministérios (2001), a Missão (CONIC, 2014), o diálogo inter-religioso (CONIC, 


\section{Revista Brasileira de Diálogo Ecumênico e Inter-religioso}

2011.) e a Declaração ecumênica sobre a água como direito humano e bem público (CONIC, 2005). Também os seminários das Comissões de Diálogo Bilateral possibilitam convergências e, por vezes, consenso mesmo. Citamos aqueles da Comissão Católica-Luterana: a doutrina da justificação por graça e fé (1998), a hospitalidade eucarística (1998), os ministérios (2000), “A tradição apostólica" (2004), entre outros, cujos resultados foram publicados mas, infelizmente, ainda pouco conhecidas. É também um resultado do empenho ecumênico o crescimento da reflexão teológica em perspectiva ecumênica em muitos Institutos e Faculdades de Teologia como na PUCPR que atualmente possui três professores da graduação e da pós-graduação em teologia peritos do ecumenismo, com linhas de pesquisa e projetos específicos, além de contarem com cerca de 20 alunos e alunas orientados para mestrado e doutorado em temas de ecumenismo e diálogo inter-religioso. Da mesma forma a faculdade de Ciências da Religião da Universidade Federal de Juiz de Fora, há anos desenvolve projetos de pesquisa em nível de excelência promovendo o diálogo inter-religioso. Esses não se configuram como os únicos espaços acadêmicos onde se aprofunda a reflexão teológica, mas ilustram a busca por estudos nas áreas de ecumenismo e diálogo inter-religioso como uma exigência que responde a uma demanda cada vez mais frequente em nosso mundo plural. Como consequência, cresce a produção de bibliografia de autores brasileiros neste campo.

Destaque especial é preciso dar à RELEP. A sigla designa a Rede Latino-Americana de Estudos Pentecostais. Trata-se de uma organização que reúne cerca de 80 pesquisadores no Brasil, comprometidos com o estudo crítico e interdisciplinar da experiência pentecostalcarismática. Esses pesquisadores lideram diversos projetos, em Universidades e, por sua vez, integram-se à Rede mais ampla, com outros pesquisadores na América Latina. A RELEP, como diz o nome, tem uma dinâmica de rede, congregando pesquisadores pentecostais, protestantes e um pequeno grupo de católicos e funciona com uma dupla face: a face interconfessional, abrangendo aproximadamente doze denominações de toda a América Latina, com articulações junto ao Fórum Cristão Global (Global Christian Forum); e uma face acadêmica, pois a RELEP no Brasil é formada por teólogos e cientistas da religião, oficialmente inscrita como Grupo de Pesquisa na CAPES. Seus membros são todos acadêmicos, de diferentes Faculdades e Universidades brasileiras.

\subsection{Espiritual}

Em muitas comunidades realiza-se, anualmente, a Semana de Oração pela Unidade dos Cristãos (ver o crescimento da venda de livros no CONIC). É estimulador o fato de vermos crescer em muitos ambientes o desenvolvimento de uma "espiritualidade do diálogo", sedimentando a prática e a reflexão ecumênicas.

Uma grande novidade na dimensão espiritual foi nestes últimos anos o diálogo com o mundo pentecostal e neo-pentecostal. É preciso sinalizar o surgimento de dois movimentos muito significativos que estão se consolidando a cada ano.

Caminhos de Diálogo, Curitiba, ano 7, n. 10, p. 124-131, jan./jun. 2019

126 ISSN 2595-8208 


\subsection{ENCRISTUS}

A sigla ENCRISTUS quer dizer Encontro de Cristãos em busca de Unidade e Santidade. A experiência começou em 2007, tendo já ultrapassado dez anos de atividade. Tratase de um encontro de cristãos, irmanados pelo Batismo, que se sentiram movidos pela oração de Jesus: "Pai, que sejam um, para que o mundo creia" (Jo 17,21-23). A partir desta moção sentida no coração pela escuta da Palavra - evangélicos e católicos começaram a se encontrar a cada ano ou em âmbito nacional ou regionaL. (São Paulo, Minas Gerais, Rio de Janeiro e Paraná - estados do Brasil).

Os participantes assumem o lema de Unidade em santidade e santidade em unidade para expressar o propósito de Deus para a Igreja: povo sacerdotal, profético e real, vocacionado à comunhão. Os participantes do ENCRISTUS acolhem este chamado de Deus - cada qual buscando santidade e unidade a partir de suas Comunidades e Igrejas, onde vivem a fé cotidianamente. Numa perspectiva de unidade, católicos e evangélicos participantes entendem que esta vocação aproxima a todos os batizados; pois além de professarem a Jesus como Redentor e partilharem o Credo Apostólico, esses cristãos têm outra característica em comum: experimentam a efusão dos dons do Espírito Santo, vivendo a espiritualidade de um "novo e contínuo Pentecostes" "que se configura como exercício dos carismas para a missão e a edificação da Igreja. Podemos dizer, em síntese, que o ENCRISTUS é um encontro de católicos e evangélicos que partilham entre si a graça do novo Pentecostes, dispostos a trilhar juntos um percurso de unidade e santidade.

\subsection{Conferência "Somos um"}

A Conferência Internacional Somos Um é um encontro que reúne católicos, pentecostais e algumas representações protestantes, da América do Norte, América Central, América do Sul e Europa. Acontece no Rio de Janeiro há cerca de seis anos; mas ganhou envergadura internacional a partir de 2017, na esteira dos encontros do ENCRISTUS no Rio de Janeiro. Insere-se como evento reconhecido pela Arquidiocese do Rio de Janeiro, promovido pela Comunidade Coração Novo (católica), com o trabalho de Comissões ecumênicas para tarefas específicas. Informações são acessíveis no site: www.missaosomosum.com.br. A finalidade da Conferência Somos Um é reunir e articular em contato fraterno, mediante oração, testemunho e ensino (conferências temáticas) tanto de líderes quanto de simples membros de

\footnotetext{
${ }^{1}$ Expressão citada à conclusão do documento Orientaçães teológicas e pastorais sobre a Renovação Carismática Católica, resultante dos primeiros Diálogos de Malines sobre o movimento carismático, com a coordenação do Cardeal Suenens. Cf. SUENENS, Léon-Joseph (coord.). Orientações teológicas $e$ pastorais da Renovação Carismática Católica. $3^{\text {a }}$ ed. São Paulo: Loyola, 1979, p. 75. Não se trata de "outro" Pentecostes, como se o primeiro de At 2 fosse um mero fato histórico; mas sim de um novo ou renovado Pentecostes, que atualiza os carismas na Igreja de hoje, como o mesmo Suenens propõe. Cf. SUENENS, Léon-Joseph. A renovação carismática: um novo Pentecostes? $3^{\mathrm{a}}$ ed. São Paulo: Paulus, 1999.
} 


\section{Revista Brasileira de Diálogo Ecumênico e Inter-religioso}

Igrejas, Ministérios e Movimentos de expressão pentecostal-carismática comprometidos com a unidade dos cristãos. A espiritualidade de fundo é a reconciliação, a começar dos membros batizados do Corpo de Cristo, chamados a testemunhar a unidade em amor (cf. 2Cor 5,16-21).

Os resultados ecumênicos nesses três horizontes tem importantes consequências eclesiológicas: estamos aprendendo a ser uma Igreja mais plural, policêntrica, participativa, integrada, fraterna e ecumênica.

\section{PERSPECTIVAS FUTURAS}

Não obstante os frutos colhidos, os obstáculos também são perceptíveis. O movimento ecumênico sente uma espécie de cansaço pelo atraso da comunhão tão desejada. Posturas de lideranças eclesiásticas por vezes fragilizam a convicção alicerçada nessa longa caminhada e em muitos ambientes, o espírito de diálogo, respeito mútuo e cooperação cede lugar a atitudes fundamentalistas e exclusivistas, atrasando a recepção dos frutos obtidos pelo exercício do diálogo na estrutura das Igrejas.

Explicitamos mais longamente alguns outros desafios:

a) situar-se dialogicamente no contexto religioso plural e discernir seus desdobramentos. Cresce em nosso país a diversidade religiosa e a fragmentação sempre mais intensa do cristianismo. Nesse contexto há tensões e conflitos, atitudes de fundamentalismo, discriminação, preconceito e proselitismo.

O marketing religioso midiático gera desenraizamento da vida de fé. Em busca de autodefesa, grupos religiosos radicalizam suas posturas teológicas, espirituais e pastorais, intensificando o clima de polêmica e controvérsia. Por vezes as próprias Igrejas são causa de divisão. Por isso o caminho rumo à unidade exige assumir os pecados, buscar o perdão e retomar a caminhada. A nossa preocupação com a diversidade religiosa e eclesial é legítima. Contudo, por vezes fragiliza a convicção do diálogo e mostra um ecumenismo recuado quando não acuado. Urge um discernimento apurado dos fatores da diversidade religiosa e de expressões da espiritualidade do nosso tempo, mas sem buscar simplesmente uma auto-defesa que nos afaste dos caminhos do diálogo, da cooperação e da afirmação do princípio da liberdade religiosa (Dignitatis humanae). Contudo assistimos ao surgimento de fatores complicadores nesse processo.

Há alguns anos, percebe-se uma crescente organização política partidária por parte de evangélicos, particularmente os de matriz pentecostal/neopentecostal. Tal percepção se tornou ainda mais clara com a consolidação da chamada "bancada da bíblia", composta, a partir das eleições de 2018, por aproximadamente noventa (90) deputados e senadores. É uma realidade passível de consideração e nada desprezável. Uma das principais observações feitas por juristas e operadores do Direito, é quanto ao risco, sempre presente, de demasiada influência de doutrinas religiosas confessionais ou específicas no processo legislativo e, até mesmo, judiciário. Embora haja doutrinas judiciais que reconheçam a interpenetração de elementos Caminhos de Diálogo, Curitiba, ano 7, n. 10, p. 124-131, jan.jun. 2019 
Morais no Ordenamento, é necessário sempre recordar a liberdade desse frente àqueles. Por mais elaborada e consistente que seja, nenhuma moral religiosa específica pode arrogar-se a faculdade de tornar-se critério de elaboração legislativa. Caso contrário, ferir-se-á o princípio da laicidade do Estado. No entanto, o princípio ora mencionado não é sinônimo de desconsideração do fenômeno religioso e suas significativas influências no cotidiano da sociedade. Há que se considerar com honestidade e vênia a contribuição que as variadas expressões religiosas oferecem aos povos em que se encontram. Todavia, a contribuição das doutrinas confessionais nas atividades legiferantes reside na oferta e na defesa de valores universais que salvaguardem a dignidade de toda vida e da vida toda, superando, assim, a promoção de elementos específicos e particulares de uma única expressão religiosa. Preocupa o fato que não parece ser essa a intenção no hodierno cenário sócio-político e religioso brasileiro.

b) Fortalecer as estruturas de diálogo que possuímos. Isso acontece assumindo com convicção as suas agendas ecumênicas. Falamos aqui do CONIC, da CESE, das Comissões bilaterais, entre outras, mas também da Comissão Episcopal Pastoral para o Ecumenismo e o Diálogo Inter-religioso da CNBB. Essas estruturas possuem certa fragilidade que em muito expressa a fragilidade das convicções ecumênicas das Igrejas membro. A diversidade dos parceiros mostra quão exigente é o exercício do diálogo que ali se realiza. Mas com métodos esclarecidos para o diálogo podemos avançar na realização dos objetivos a que se propõe. Essas estruturas precisam ser compreendidas como "estruturas de Igreja", que promovem o testemunho comum do Evangelho. Elas possibilitam um processo de aprendizagem, de conhecimento mútuo, de troca de experiências, da consciência e prática da solidariedade, o compromisso com a verdade, a realização de iniciativas missionárias e diaconais peculiares.

c) Intensificar a recepção do ensino ecumênico do Vaticano II, do magistério eclesial posterior, das Assembleias do episcopado latino-americano e dos trabalhos das Comissões Bilaterais de Diálogo. Os documentos conciliares como Unitatis redintegratio, Nostra aetate, Dignitatis humanae, a Encíclica Ut unum sint e o ensino do atual pontífice, o Papa Francisco, justificam a causa ecumênica como causa da Igreja: "toda a vida dos cristãos está marcada pela solicitude ecumênica" (Ut unum sint, 15). O papa Bento XVI pediu na Assembleia de Aparecida que o ecumenismo seja uma convicção concreta, ele "precisa de gestos concretos, capazes de tocar nos corações e sacudir as consciências" dos cristãos e das igrejas (DAp n. 234). Corrobora essa exortação a afirmação do papa Francisco: "Devemos sempre lembrar-nos de que somos peregrinos, e peregrinamos juntos. Para isso, devemos abrir o coração ao companheiro de estrada sem medos nem desconfianças, e olhar primariamente para o que procuramos: a paz no rosto do único Deus" (Evangelii gaudium, 244). Urge conhecer e assumir também os resultados do diálogo teológico que realizamos há mais de 50 anos. A recepção do magistério da Igreja no campo ecumênico, do ensino teológico e dos resultados dos diálogos precisa ser estrutural, teológica, espiritual e pastoral. Somente assim ela terá incidência no ser e agir da Igreja, ampliando as fronteiras epistemológicas da nossa fé e tornando mais acolhedoras as nossas 


\section{Revista Brasileira de Diálogo Ecumênico e Inter-religioso}

estruturas. Isso é muito mais que obediência ao magistério eclesial, é fidelidade à vontade de Cristo para a sua Igreja: "Pai, que todos sejam um, para que o mundo creia" (Jo 17,21).

d) Parceria com diferentes formas de construir a oikoumene: sabemos que o movimento ecumênico é uma realidade dinâmica e em contínua transformação a partir dos novos tempos, novos contextos e novos sujeitos que se integram no diálogo sobre a oikoumene. Identificamos atualmente 4 significados desse termo:

1) ecumenismo secular: propõe novas formas de estar no mundo, um ecumenismo da justiça e das culturas, com força para promover a paz, afirmando assim que "outro mundo é possível";

2) ecumenismo inter-religioso (diálogo inter-religioso): assentado no princípio teocêntrico, extrapolando o universo cristão, como o que melhor pode responder às interpelações de uma realidade religiosa plural;

3) ecumenismo espiritual: busca vincular diferentes motivações fundantes da existência humana, propondo um horizonte holístico no qual comungam em seus princípios gerais sobre a origem, o sentido e o final da existência;

4) ecumenismo cristão: continuidade da busca a unidade da Igreja. Entendemos que nessas propostas há um princípio realista do ecumenismo que se afirma a partir da realidade concreta de cada uma das identidades em diálogo; e um princípio utópico, que crê ser possível a convivência fraterna de todas as identidades que constroem a oikoumene. Como Igreja, nos mantemos no universo do ecumenismo cristão, e aí buscamos fortalecer duas principais atitudes: a primeira consiste em ter claro o que, realmente, motiva o nosso empenho ecumênico, isto é: o princípio da fé em Cristo, o mandato evangélico de Jo 17,21, a consciência eclesial e o vínculo entre ecumenismo e missão; e a segunda visa dialogar e interagir com quem propõe outras formas de ecumenismo, buscando tecer parcerias sem prejuízo ao Evangelho e à Igreja. Afinal, não somos os únicos atores e destinatários da oikoumene do Reino.

Finalmente, cabe a pergunta: como prosseguir no caminho ecumênico? Em primeiro lugar, pelo fortalecimento do patrimônio comum na fé dos cristãos. Como afirmou Bento XVI: "A coisa mais necessária para o ecumenismo é primariamente que, sob a pressão da secularização, não percamos, quase sem dar conta disso, as grandes coisas que temos em comum, que por si mesmas nos tornam cristãos e que nos ficaram como dom e tarefa. O erro do período confessional foi ter visto, na maior parte das coisas, apenas aquilo que separa, e não ter percebido de modo existencial o que temos em comum nas grandes diretrizes da Sagrada Escritura e nas profissões de fé do cristianismo antigo. Para mim, isto constitui o grande progresso ecuménico dos últimos decénios: termo-nos dado conta desta comunhão e, no rezar e cantar juntos, no compromisso comum em prol da ética cristã face ao mundo, no testemunho comum do Deus de Jesus Cristo neste mundo, reconhecermos tal comunhão como o nosso comum e imorredouro alicerce. É certo que o perigo de a perder não é irreal.” (Erfurt, 23 de Caminhos de Diálogo, Curitiba, ano 7, n. 10, p. 124-131, jan./jun. 2019 130 ISSN 2595-8208 
Análise de conjuntura eclesial na perspectiva do ecumenismo setembro de 2011). Em segundo lugar é necessário intensificar os esforços por uma formação ecumênica consequente e de acordo com as demandas do momento presente e por fim precisa renovar os nossos compromissos com as Igrejas e as organizações parceiras do diálogo.

Para isso nos deixamos guiar pelo Espírito que une os cristãos numa só fé e num só batismo, para a edificação do único Corpo de Cristo (cf. Ef 4,4), a sua Igreja. Perseveramos na tarefa que nos é dada pelo próprio Cristo: "Que todos sejam um, para que o mundo creia"(Jo 17,21). Por isso o serviço ecumênico se faz um "ministério de reconciliação"(2Cor 5,18). E para vive-lo seguimos a orientação de Paulo: "Eu, prisioneiro no Senhor, vos exorto a levardes uma vida digna da vocação que recebestes: com toda humildade e mansidão e com longanimidade, suportai-vos uns ao outros no amor, solícitos em guardar a unidade do Espírito, pelo vínculo da paz" (Ef 4,1-3). O princípio da caridade é que nos une e nos motiva no trabalho ecumênico: "Se vos amardes uns aos outros, todos reconhecerão que sois meus discípulos"(Jo 13,35). Para isto trabalhamos. Que o Espírito da Unidade nos oriente e nos sustente na nossa caminhada rumo à unidade do único Corpo de Cristo. 